\title{
A Deep Blue B,N-Doped Heptacene Emitter That Shows Both Thermally Activated Delayed Fluorescence and Delayed Fluorescence by Triplet-Triplet Annihilation
}

Subeesh Madayanad Suresh, Eimantas Duda, David Hall, Zhen Yao, Sergey Bagnich, Alexandra M. Z. Slawin, Heinz Bässler, David Beljonne, Manfred Buck,* Yoann Olivier,* Anna Köhler,* and Eli Zysman-Colman*

Cite This: J. Am. Chem. Soc. 2020, 142, 6588-6599

Read Online

ABSTRACT: An easy-to-access, near-UV-emitting linearly extended B,Ndoped heptacene with high thermal stability is designed and synthesized in good yields. This compound exhibits thermally activated delayed fluorescence (TADF) at ambient temperature from a multiresonant (MR) state and represents a rare example of a non-triangulene-based MR-TADF emitter. At lower temperatures triplet-triplet annihilation dominates. The compound simultaneously possesses narrow, deep-blue emission with CIE coordinates of $(0.17,0.01)$. While delayed fluorescence results mainly from triplet-triplet annihilation at lower temperatures in THF solution, where aggregates form upon cooling, the TADF mechanism takes over around room temperature in solution when the aggregates dissolve or when the compound is well dispersed in a solid matrix. The potential of our molecular design to trigger TADF in larger acenes is demonstrated through the accurate prediction of

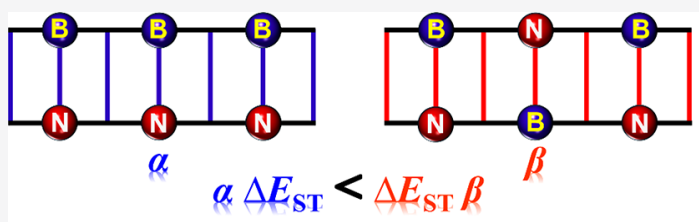
$\Delta E_{\mathrm{ST}}$ using correlated wave-function-based calculations. On the basis of these calculations, we predicted dramatically different optoelectronic behavior in terms of both $\Delta E_{\mathrm{ST}}$ and the optical energy gap of two constitutional isomers where only the boron and nitrogen positions change. A comprehensive structural, optoelectronic, and theoretical investigation is presented. In addition, the ability of the achiral molecule to assemble on a $\mathrm{Au}(111)$ surface to a highly ordered layer composed of enantiomorphic domains of racemic entities is demonstrated by scanning tunneling microscopy.

\section{INTRODUCTION}

The high charge carrier mobility of graphene ${ }^{1,2}$ is an extremely appealing property that can be exploited in electrode design ${ }^{3}$ for optoelectronic devices. To extend the applicability of graphene and its derivatives, the structure of the materials must be modified to modulate their band gaps. Reducing the dimensionality of graphene in the form of graphene quantum dots and graphene nanoribbons is one way to induce a defined band gap that overlaps with the visible spectrum in these materials. ${ }^{4}$ Another strategy to modulate the optoelectronic properties of nanographenes, which are graphenoid fragments, involves heteroatom doping. In particular, boron-, nitrogen-, sulfur-, and phosphorus-doped organic nanographene materials have been identified as possessing useful properties in energyrelated research such as supercapacitors, ${ }^{5-8}$ lithium ion batteries, ${ }^{9-12}$ fuel cells, ${ }^{13-16}$ solar cells, ${ }^{17-19}$ and sensors. ${ }^{20-23}$ Recent advances in synthetic methodology in the form of surface-assisted coupling ${ }^{24-27}$ or amplified growth ${ }^{28-30}$ have permitted access to heteroatom-doped nanographene materials. The smallest heteroatom-doped nanographene compounds are frequently readily synthesized in good yields by using intra- molecular Friedel-Crafts-type reaction. However, this synthetic approach demands the availability of electron-rich precursor molecules containing functional groups such as hydroxyl, ${ }^{31,32}$ amino, ${ }^{33-37}$ imino, ${ }^{38,39}$ halogeno, ${ }^{40-42}$ or trimethylsilyl groups, ${ }^{43,44}$ which necessitates often a multistep synthesis of these precursors.

In 2015, Hatakeyama et al. ${ }^{45}$ introduced a one-step borylation method to generate polycyclic aromatic hydrocarbons (PAHs) with a 1,4-oxoborine substructure through ortho-lithiation of 1,4-diaryloxybenzenes and subsequent transmetalation to boron, followed by electrophilic borylation of the arene. Later, the same group demonstrated the versatility and the impact of the one-step borylation through the synthesis of boron- and nitrogen-containing PAHs, which they showed to be high-

Received: December 19, 2019

Published: March 5, 2020 


\section{Previous work}

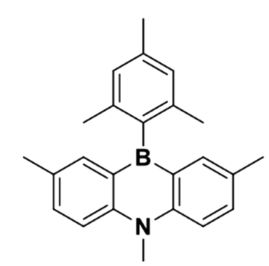

9, $\lambda_{\mathrm{PL}}=421 \mathrm{~nm}$, $\Phi_{\mathrm{PL}}=48 \%$, cyclohexane Fluorescent

Org. Lett., 2006, 8, 2241-2244<smiles>CCCCc1ccc2c(c1)B(c1cc(C)cc(C)c1Cc1cc(C)cc(C)c1B1c3cc(CCCC)ccc3N(C)c3cc4c5cc(CCCC)ccc5n(C)c4cc31)c1cc(C)cc(C)c1-2</smiles>

$4, \lambda_{\mathrm{PL}}=428 \mathrm{~nm}$, $\Phi_{\mathrm{PL}}=21 \%$, cyclohexane Fluorescent

Org. Lett., 2006, 8, 2241-2244

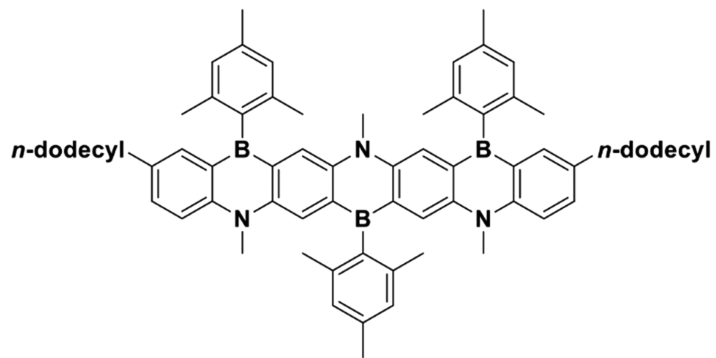

$8, \lambda_{\mathrm{PL}}=625 \mathrm{~nm}$, $\Phi_{\mathrm{PL}}=55 \%$, cyclohexane Fluorescent

Org. Lett., 2006, 8, 2241-2244<smiles>CCCCc1ccc2c(c1)B(c1c(C)cc(C)cc1C)c1cc3c(cc1N2C)B(c1c(C)cc(C)cc1C)c1cc(CCCC)ccc1N3C</smiles>

3, $\lambda_{\mathrm{PL}}=534 \mathrm{~nm}$, $\Phi_{\mathrm{PL}}=69 \%$, cyclohexane Fluorescent

Org. Lett., 2006, 8, 2241-2244

\section{Present work}

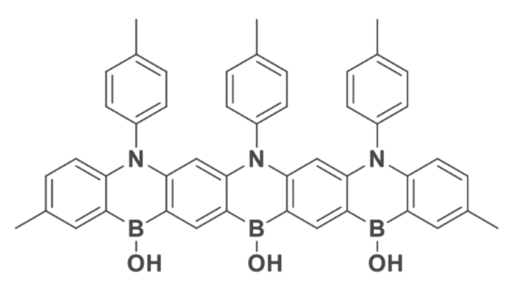

$\boldsymbol{\alpha}$-3BNOH, $\lambda_{\mathrm{PL}}=390 \mathrm{~nm}(300 \mathrm{~K})$

$\Phi_{\mathrm{PL}}=38 \%($ Air $), 50 \%\left(\mathrm{~N}_{2}\right)$, THF

TADF

Figure 1. Chemical structures of previously reported B,N-doped acenes and the structure of our molecule.

performance blue-emitting thermally activated delayed fluorescence $(\mathrm{TADF})$ materials for organic light-emitting diodes (OLEDs). The synthetic protocols were further simplified, and a series of B,N-doped nanographenes could be obtained in a twostep synthesis consisting of a key multiborylation of a triarylamine intermediate. By adjusting the boron source, Brønsted base, and reaction temperature, selectively doublely and triply borylated products could be obtained. ${ }^{45-50}$

Among the striking advantages of these molecules is their narrow emission spectra (FWHM $=14-40 \mathrm{~nm}$ ) compared to the conventional donor-acceptor TADF molecules (FWHM = $70-100 \mathrm{~nm}$ ) because of their low reorganization energy. The origin of the $\mathrm{TADF}$ in these compounds originates from the combination of short-range charge transfer and delocalized hole and electron wave functions that effectively reduces the exchange and the singlet-triplet energy gap while maintaining a large radiative decay rate. ${ }^{51}$ Since 2016 , a number of improvedperformance $\mathrm{B}, \mathrm{N}$-doped analogues all showing multi-resonant
TADF (MR-TADF) have been developed as emitters for OLEDs.

Incorporating main group elements into the framework of larger acenes was previously known as a very effective strategy to tune the property of the parent $\pi$-conjugated systems, ${ }^{52}$ which are otherwise inaccessible in non-heteroatom-doped acenes. In particular, the integration of tricoordinate boron atoms within the PAH can result in the emergence of new optoelectronic properties. In 2006, Kawashima et al. reported a series of laddertype fused azaborines by extending the number of boron and nitrogen atoms in the aromatic acenes. ${ }^{53}$ In each of the examples shown in Figure 1, the boron and nitrogen atoms are disposed para with respect to each other-a regiochemistry that is necessary but not sufficient to turn on TADF in multiresonance emitters. As the conjugation length of the B,N-doped acenes is extended in the series where the relative positions of the boron and nitrogen atoms alternate, there is a pronounced observed red-shift of the photoluminescence (PL) spectrum from 9 to 3 to 8. Surprisingly, when there is a regioregular extension of the 
Scheme 1. Synthesis of $\alpha-3 \mathrm{BNOH}^{a}$

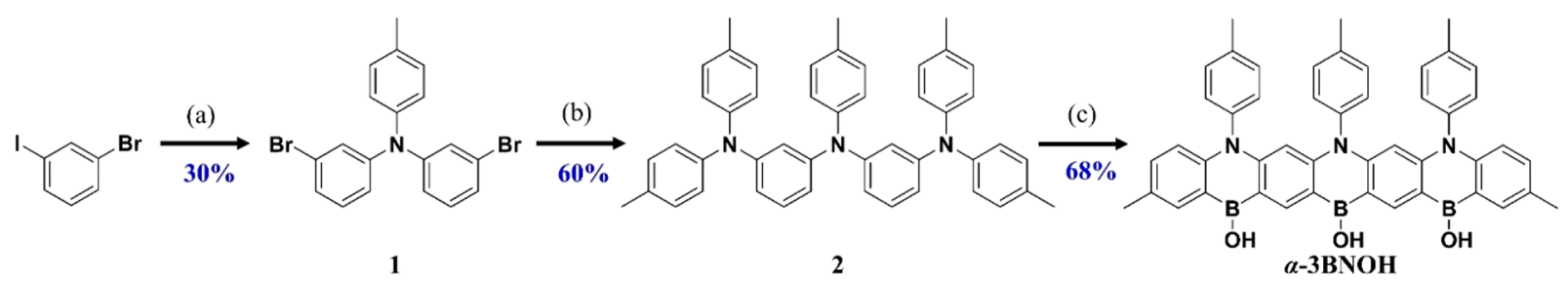

${ }^{a}$ Reagents and conditions: (a) $p$-toluidine, $\mathrm{Cu}, \mathrm{CuI}, \mathrm{K}_{2} \mathrm{CO}_{3}$, reflux 5 days; (b) di-p-tolylamine, $\mathrm{Pd}(\mathrm{OAc})_{2},\left[(t \text { - } \mathrm{Bu})_{3} \mathrm{PH}\right] \mathrm{BF}{ }_{4}, \mathrm{NaO}$ - $\mathrm{Bu}$, toluene, 110 ${ }^{\circ} \mathrm{C}, 24 \mathrm{~h}$; (c) $\mathrm{BBr}_{3}, 1,2-4$-trichlorobenzene, $200{ }^{\circ} \mathrm{C}, 12 \mathrm{~h}$.

(a)

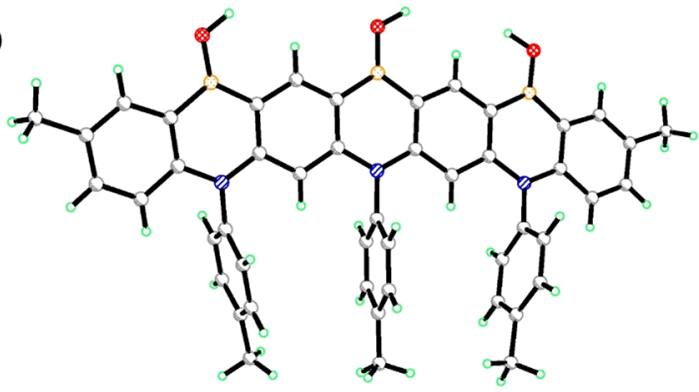

(b)

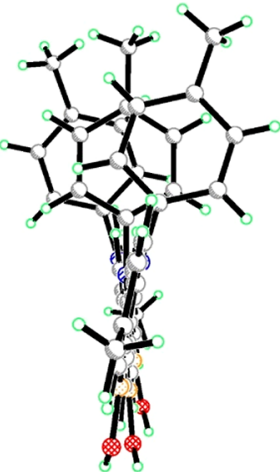

(c)

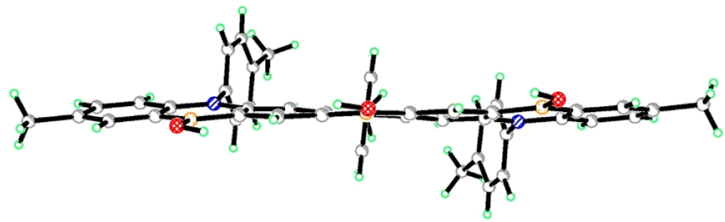

Figure 2. ORTEP diagram of (a) $\alpha-3 \mathrm{BNOH}$ obtained by single crystal X-ray analysis (b) and (c) side views. Thermal ellipsoids are displayed at $50 \%$ probability level.

$\mathrm{B}, \mathrm{N}$-doping, as in 4, extended conjugation across the acene is suppressed, which leads to a very small red-shift of the PL spectrum upon extension of the acene (compare 3 vs 4 ); these compounds were identified as fluorescent materials, and a detailed photophysical study of these B.N-doped acenes was not provided.

\section{RESULTS AND DISCUSSION}

In the context of our previous theoretical study that predicted that higher-order $\mathrm{B}, \mathrm{N}$-doped acenes should show promisingly small $\Delta E_{\mathrm{ST}}$ and high oscillator strength, and mindful of the limited prior art summarized above, we targeted a linearly extended $\mathrm{B}-\mathrm{N}$-doped heptacene. Compound $\alpha-3 \mathrm{BNOH}$ was obtained from a 3-fold electrophilic borylation ${ }^{49}$ of triamine $\mathbf{2}$ in good yield (Scheme 1), which itself was synthesized efficiently in two steps by a sequence of Ullman ${ }^{54}$ and Buchwald-Hartwig ${ }^{55}$ cross-coupling reactions. The $\mathrm{OH}$ functionalities are introduced during the isolation of $\alpha-3 \mathrm{BNOH}$ due to hydrolysis of the $\mathrm{B}-\mathrm{Br}$ bonds. Extracting the crude reaction mixture in EtOAc followed by aqueous wash afforded crude $\alpha-3 \mathrm{BNOH}$, which was then redissolved in $\mathrm{MeCN}$ and placed in an ultrasonic bath for 15 min. The formed off-white precipitate was then filtered and washed with acetonitrile, DCM, and hexane and dried to afford pure $\alpha-3 \mathrm{BNOH}$. The identity and purity of $\alpha-3 \mathrm{BNOH}$ were established from a combination of ${ }^{1} \mathrm{H}$ and ${ }^{13} \mathrm{C}$ NMR spectroscopy, high-resolution mass spectrometry, elemental analysis, and single crystal X-ray diffraction analysis. High thermal stability was noted for $\alpha-3 \mathrm{BNOH}$ based on thermogravimetric analysis (TGA). The decomposition temperature $\left(T_{\mathrm{d}}\right)$, defined as the $5 \%$ weight loss of the material, was calculated to be $554{ }^{\circ} \mathrm{C}$ (Figure S10).

Single crystal analysis was performed to identify the structural orientation of $\alpha-3 \mathrm{BNOH}$ (Figure 2) in the solid state. The three tolyl rings attached to the nitrogen are aligned nearly orthogonally (torsion angles: $86^{\circ}-95^{\circ}$ ) to the heptacene core, which is likely to reduce the impact of possible $\pi-\pi$ interactions in the unit cell. The hydroxyl groups on the boron participate in hydrogen bonding with the THF solvent molecules in the crystal. There are no other intermolecular short contacts of note. In line with previous reports, ${ }^{45,49} \mathrm{~B}-\mathrm{C}(1.543-1.555 \AA)$ bond lengths are longer than both $\mathrm{C}-\mathrm{C}(1.388-1.421 \AA)$ or $\mathrm{C}-\mathrm{N}$ (1.392-1.444 $\AA$ ) bonds present in the molecule. The heptacene core is nearly planar but bends because of the asymmetry in $\mathrm{C}-$ $\mathrm{B}-\mathrm{C}$ and $\mathrm{C}-\mathrm{N}-\mathrm{C}$ bond angles due to the $\pi$-stacking interactions between the pendant phenyl rings.

We then applied spin-component scaling second-order approximate coupled-cluster (SCS-CC2) to model $\alpha-3 \mathrm{BNOH}$ as well as its alternative $\mathrm{B}, \mathrm{N}$-doped heptacene analogue, $\beta$ $3 \mathrm{BNOH}$ (Figure 3). The difference density plots of both the $S_{1}$ and $\mathrm{T}_{1}$ states are reminiscent of other MR-TADF emitters where there is an alternating pattern of increasing (in yellow) and decreasing (in green) density on adjacent atoms. A smaller $\Delta E_{\mathrm{ST}}$ of $0.29 \mathrm{eV}$ was calculated for $\alpha-3 \mathrm{BNOH}$ compared to that of $\beta$ $3 \mathrm{BNOH}\left(\Delta E_{\mathrm{ST}}=0.37 \mathrm{eV}\right)$. Though somewhat higher than ideal 


\section{$\alpha-3 B N O H$}
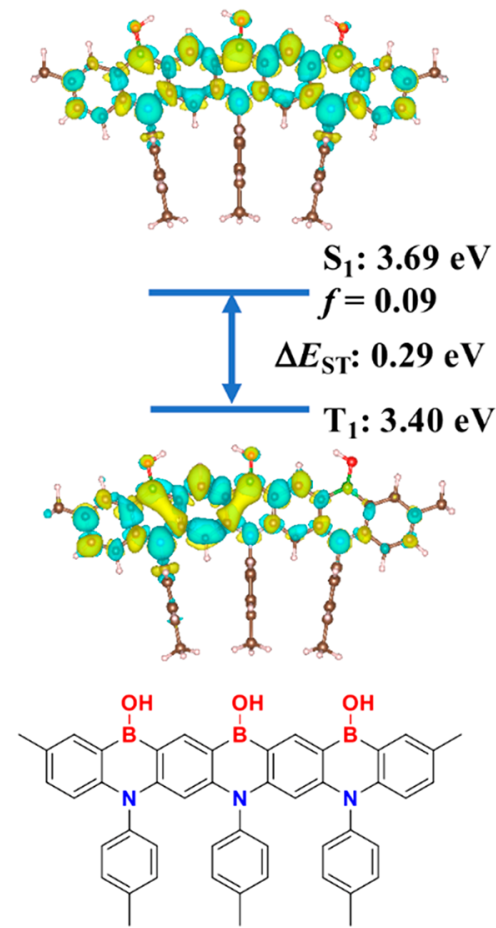

$\beta-3 B N O H$

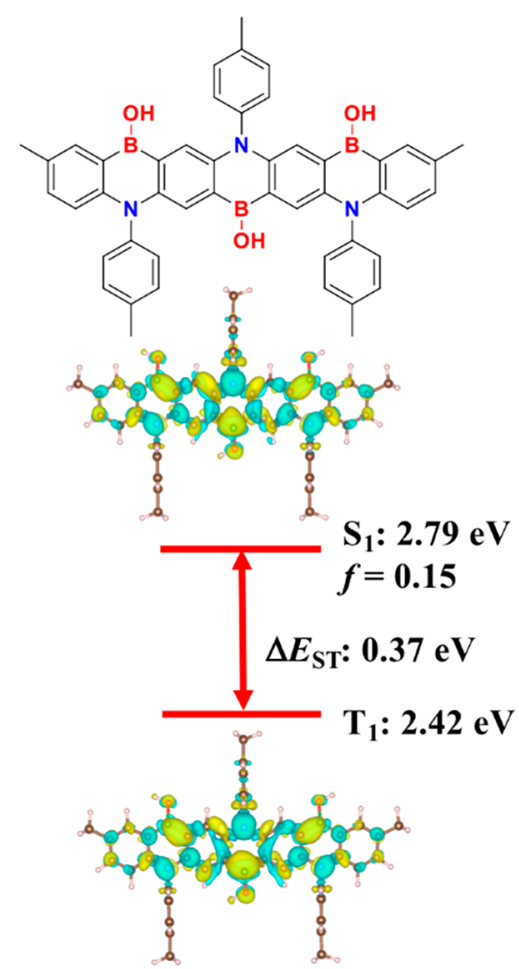

Figure 3. Different density plots for lowest singlet and triplet excited states for 3BNOH (linear, $\alpha$-, and alternating, $\beta$-isomers) calculated in the gas phase by using SCS-CC2. Blue color represents an area of decreased electron density, and yellow represents an increased electron density between the ground and excited states.

(a)

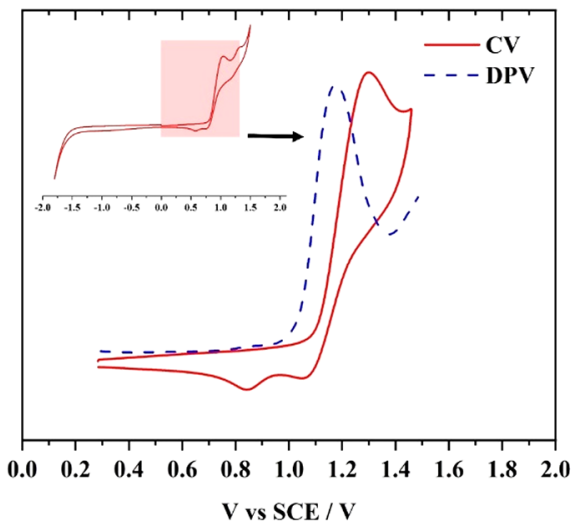

Energy / eV

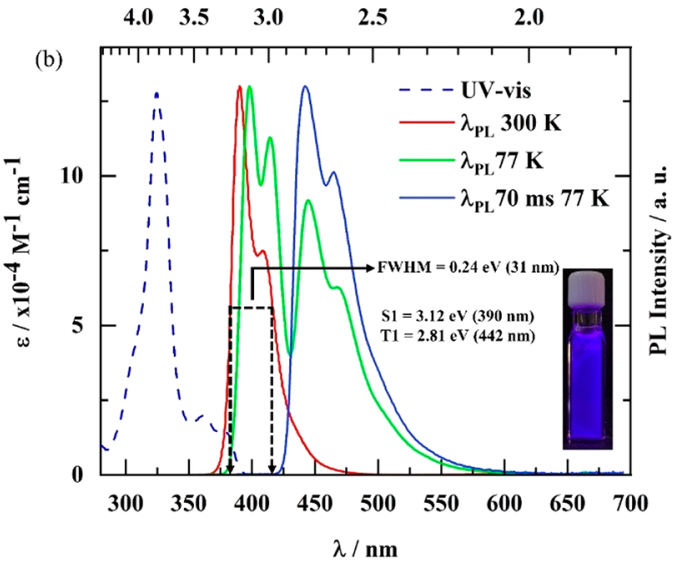

Figure 4. Solution-state optoelectronic measurements of $\alpha-3 \mathrm{BNOH}$. (a) Cyclic and differential pulse voltammograms measured in degassed THF with $0.1 \mathrm{M}\left[n \mathrm{Bu}_{4} \mathrm{~N}\right] \mathrm{PF}_{6}$ as the supporting electrolyte and $\mathrm{Fc} / \mathrm{Fc}^{+}$as the internal reference $(0.28 \mathrm{~V}$ vs SCE$){ }^{56}$ Scan rate $=100 \mathrm{mV} \mathrm{s}{ }^{-1}$. (b) Absorption, steady-state at $300 \mathrm{~K}$, and emission at $77 \mathrm{~K}$ (steady-state and with $70 \mathrm{~ms}$ delay) measured in THF and steady-state emission at $300 \mathrm{~K}$ measured in PMMA (1 wt \% emitter) spin-cast film. $\lambda_{\text {exc }}=325 \mathrm{~nm}$. Inset shows PL of $\alpha-3 \mathrm{BNOH}$ in THF at $300 \mathrm{~K}$.

for TADF emitters, we nevertheless expected that reverse intersystem crossing (RISC) would be thermally activated in $\alpha$ $3 \mathrm{BNOH}$ with potentially the assistance of higher-lying excited triplet states to the upconversion process (see Figure S12 for an energy diagram including higher-lying singlet and triplet excited states). A slightly larger oscillator strength, $f$, is predicted for $\beta$ $3 \mathrm{BNOH}(0.15)$ compared to $\alpha-3 \mathrm{BNOH}(0.09)$. Most striking is the large change in the predicted energies of the excited states, with vertical excitation from $S_{0}$ to $S_{1}$ at 3.69 and $2.79 \mathrm{eV}$ for $\alpha$ $3 \mathrm{BNOH}$ and $\beta-3 \mathrm{BNOH}$, respectively, corresponding to a difference of $0.9 \mathrm{eV}$. This prediction is consistent with the observed red-shifting of the emission in the previously reported $\mathrm{B} / \mathrm{N}$-doped heptacenes (vide supra). The HOMO and LUMO electronic distribution is provided in the Supporting Information (Figure S11).

Having completed an in silico study of $\alpha-3 \mathrm{BNOH}$ with the alternating hypothetical analogue $\beta-3 \mathrm{BNOH}$, we now turn our attention to the optoelectronic properties of the title compound. The electrochemical behavior of $\alpha-3 \mathrm{BNOH}$ was measured by cyclic voltammetry $(\mathrm{CV})$ and differential pulse voltammetry 

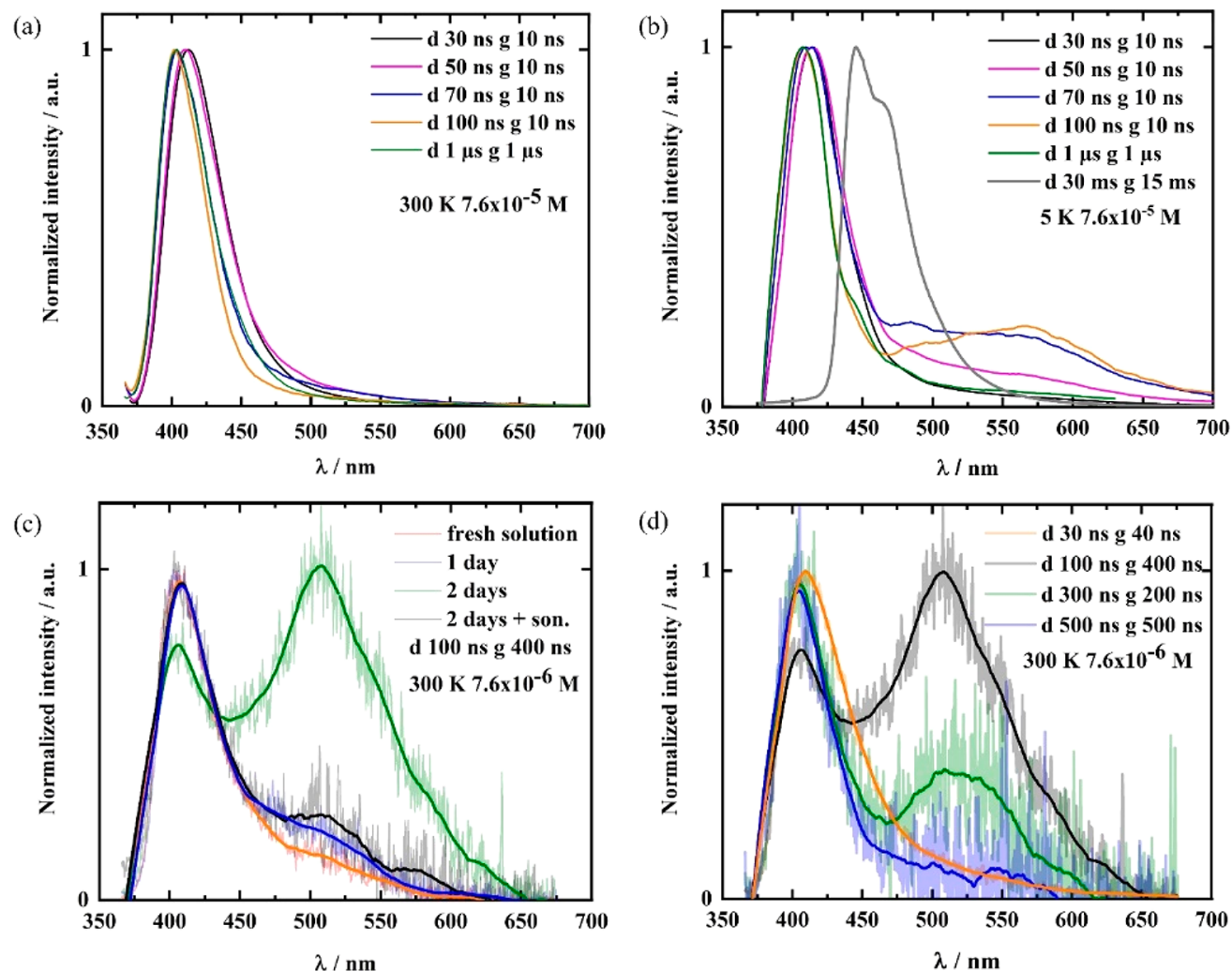

Figure 5. Emission spectra of $\alpha-3 \mathrm{BNOH}$ in THF at $7.6 \times 10^{-5} \mathrm{M}$ as indicated (a) at $300 \mathrm{~K}$ and (b) at $5 \mathrm{~K}$ for different delay times, d, and gate width, $\mathrm{g}$ (smoothed data). (c) At different times after preparation and after sonication (son), taken with a delay of $100 \mathrm{~ns}$ and a gate of $400 \mathrm{~ns}$. (d) At $300 \mathrm{~K}$ for different delay times, $\mathrm{d}$, and gate width, $\mathrm{g}$, taken in a solution 2 days after preparation. The solid lines are smoothed curves through the lighter shaded data. For all data, $\lambda_{\text {exc }}=355 \mathrm{~nm}$.

(DPV) in deaerated THF with $0.1 \mathrm{M}$ tetra- $n$-butylammonium hexafluorophosphate as the supporting electrolyte (Figure 4a). The oxidation potential, $E^{\mathrm{ox}}$, determined from the peak value of the first oxidation wave of the DPV curve is $1.17 \mathrm{~V}$ vs SCE, corresponding to a HOMO energy level of $-5.97 \mathrm{eV}\left(E_{\mathrm{HOMO}}=\right.$ $\left.-\left(E_{\text {onset }}^{\text {ox }}+4.8\right) \mathrm{eV}\right) .^{56,57}$ The oxidation is irreversible, and no reduction wave was found within the electrochemical window of the solvent. Therefore, the LUMO energy level of $-2.81 \mathrm{eV}$ was inferred by subtracting the optical energy gap, $E_{g}$, estimated from the onset of the absorption spectrum $\left(E_{\mathrm{g}}=3.16 \mathrm{eV}\right)$.

Figure $4 \mathrm{~b}$ shows the photophysical properties of $\alpha-3 \mathrm{BNOH}$ in dilute THF solutions $\left(10^{-5} \mathrm{M}\right)$. The UV-vis absorption spectrum shows a strong absorption band at $3.84 \mathrm{eV}$ (323 $\mathrm{nm})$, assigned to a $\pi-\pi^{*}$ transition. The lowest-energy absorption band is found to be at $3.27 \mathrm{eV}(379 \mathrm{~nm})$ and is seen to arise from the combined contributions of the quasidegenerate $S_{1}$ and $S_{2}$ excited states. Overall, this band appears to be significantly weaker compared to the low-energy absorption bands reported by Kawashima et al. ${ }^{53}$ for compounds 3, 4, 8, and 9 (Figure 1) where the most intense band was the lowest energy band. Quantitative agreement in the respective intensities and relative energy differences of the absorption bands is achieved between experiment and theory (see Figure S12). According to our SCS-CC 2 calculations, $S_{1}$ to $S_{3}$ excited states are expected to contribute to the lowest-energy absorption bands due to their very close energies and oscillator strengths $\left(S_{1}, S_{2}\right.$, and $S_{3}$ oscillator strengths are $0.09,0.02$, and 0.11 , respectively) while the highest-energy absorption band is assigned to $S_{4}$ (oscillator strength of 0.65 ). The larger oscillator strength calculated for $S_{4}$ than for $S_{1}$ is explained by the larger overlap between the
HOMO-2 and LUMO+1 orbitals (see Figure S12 for the orbitals plots), which are involved in the dominant one-electron transition (54\%) associated with $S_{4}$, resulting in a larger transition dipole moment in $S_{4}$ than in $S_{1}$. Similar to the emission profile reported for compound 8 (Figure 1), $\alpha$ $3 \mathrm{BNOH}$ shows structured emission. Both compounds are ladder-type heptacene-based molecules containing para-disposed boron and nitrogen atoms. Aside from the pattern of the boron and nitrogen atoms, structural differences include the substituents found at both nitrogen and boron; for compound 8 , mesityl groups are attached to boron and methyl groups are attached to nitrogen, while on $\alpha-3 \mathrm{BNOH}$ hydroxyl are substituted on boron and tolyl rings are connected to nitrogen. The photoluminescence spectrum at RT shows a structured profile with a sharp, near-UV emission band peaking at $3.18 \mathrm{eV}$ $(390 \mathrm{~nm})$ and a shoulder at $3.03 \mathrm{eV}(409 \mathrm{~nm})$. Noteworthy is the very small full width at half-maximum (FWHM) of $0.24 \mathrm{eV}$ $(31 \mathrm{~nm})$, which we attribute to the rigid nature of the compound that does not allow for torsional motions. ${ }^{58-62}$ Because of the small Stokes shift of this emission and its short lifetime (see Figure $4 \mathrm{~b}$ ), we can assign this blue emission peaking at $3.18 \mathrm{eV}$ $(390 \mathrm{~nm})$ at RT to fluorescence. By contrast, heptacene and its substituted derivatives absorb and emit in the red. ${ }^{63-66}$ The second emission band, peaking at $2.81 \mathrm{eV}$ (442 nm) with a shoulder at $(465 \mathrm{~nm})$ for $77 \mathrm{~K}$, has a long lifetime of $310 \mathrm{~ms}$ (Figure $4 b$ ), as evident from its monoexponential decay curve (Supporting Information). Because of its well-resolved vibrational structure, the large shift from the fluorescence, and the long lifetime, it can be assigned to a triplet state. When measuring under steady-state conditions at $77 \mathrm{~K}$, we observe 

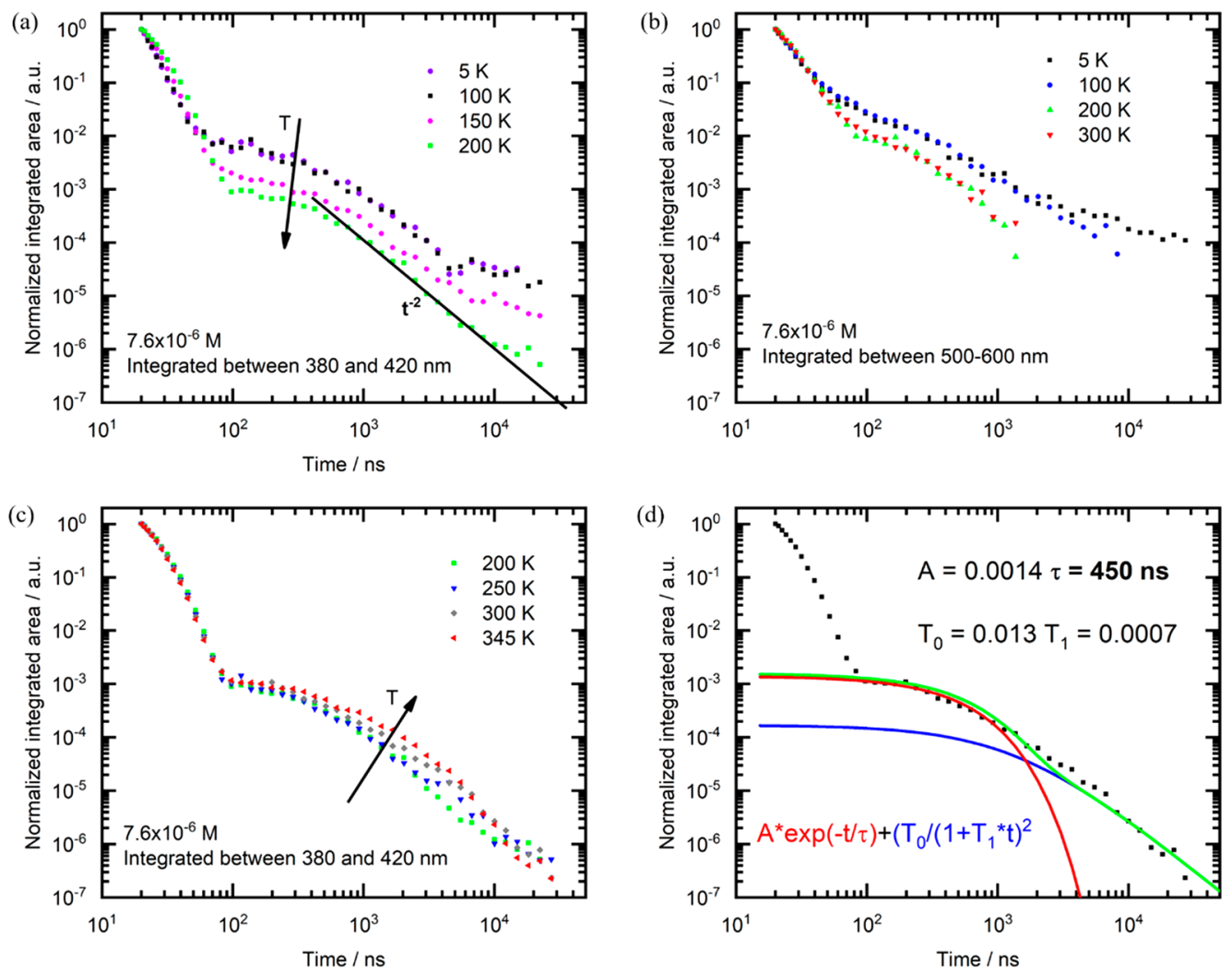

Figure 6. Photoluminescence transients taken in $7.6 \times 10^{-6} \mathrm{M}$ solution, excited at $355 \mathrm{~nm}$; (a) integrated between 380 and $420 \mathrm{~nm}$ and taken upon heating from 5 to $200 \mathrm{~K}$, with the green line indicating a slope of -2 ; (b) integrated between 500 and $600 \mathrm{~nm}$ and taken upon heating from 5 to $200 \mathrm{~K}$; (c) integrated between 380 and $420 \mathrm{~nm}$ and taken upon heating from 200 to $345 \mathrm{~K}$; (d) integrated between 380 and $420 \mathrm{~nm}$ at $300 \mathrm{~K}$. The red curve represents a monoexponential, $A \exp (-t / \tau)$, while the blue curve represents a $\left[T_{0} /\left(1+T_{1} t\right)\right]^{2}$ fit, which is characteristic for the decay of a DF caused by TTA. The green line is the sum of red and blue lines. The fitting parameters are shown in the figure.

both the fluorescence and the phosphorescence components. The $\Delta E_{\mathrm{ST}}$, determined from the $0-0$ peaks of the two bands at $77 \mathrm{~K}$, is measured to be $0.31 \mathrm{eV}$, consistent with our SCS-CC2 calculations. The absolute photoluminescence quantum yield, $\Phi_{\mathrm{PL}}$, in $7.6 \times 10^{-5} \mathrm{M}$ THF at RT is $50 \%$, which reduces to $38 \%$ upon exposure to air (Figure S13).

To obtain a deeper insight, we performed further photoluminescence measurements as a function of temperature, concentration, delay time after pulsed excitation, and gate width. Figure 5 shows the relevant spectra. For a $7.6 \times 10^{-5} \mathrm{M}$ solution at room temperature (Figure 5a), we observe essentially the same fluorescence spectrum for all delay times for short gate times of $10 \mathrm{~ns}$, albeit there is some small hypsochromic shifting of the emission with increasing delay times. We point out that the resolution of the detector used for the time-resolved measurements of Figure 5 is lower than that of the spectrometer used for Figure 4, in particular in the blue spectral range. After a longer delay time of $1 \mu \mathrm{s}$ and gate width of $1 \mu \mathrm{s}$, we still observe the same deep blue emission, which clearly indicates an origin that involves intermediate long-lived triplet states.

To observe phosphorescence, it is necessary to cool the solution, e.g., by forming a glass at $5 \mathrm{~K}$ (Figure $5 \mathrm{~b}$ ). By use of a long delay time of $30 \mathrm{~ms}$ and gate width of $15 \mathrm{~ms}$, the structured phosphorescence spectrum is clearly visible. The fluorescence band shows the same small hypsochromic shift with increasing delay times as already observed at room temperature. In addition, a broad, unstructured band emerges in the green-tored spectral range at short times that has fully disappeared by the microseconds time scale. The broadness and lack of feature along with the red-shift compared to the fluorescence band near $400 \mathrm{~nm}$ and the intermediate lifetime of $<1 \mu \mathrm{s}$ is suggestive of an origin from a physical dimer or aggregate that may have formed when cooling; the driving force for aggregate formation at high dilution may be due in part to intermolecular hydrogen bonding as was observed by STM on gold surfaces (vide infra). To address this, we measured the PL in a freshly prepared, more dilute solution of $7.6 \times 10^{-6} \mathrm{M}$, using a delay of $100 \mathrm{~ns}$ and a 400 $\mathrm{ns}$ gate width (Figure $5 \mathrm{c}$ ). Around $500 \mathrm{~nm}$, there is only a weak signal that can hardly be distinguished from the fluorescence tail (red curve). When repeating the measurement after 1 day (blue curve) and after 2 days (green curve), a band centered at $500 \mathrm{~nm}$ emerges. After sonication of the solution for a few minutes, this signal disappeared (black curve). On the basis of this observation, we associate the broad emission centered at 500 $\mathrm{nm}$ to interactions between adjacent chromophores, such as those prevailing in excimers, physical dimers, or aggregates. ${ }^{62}$ As molecular motion or reorientation is severely restricted at $5 \mathrm{~K}$, the most likely origin of the emission is rather weakly bound $\mathrm{H}$ type aggregates. Figure 5d displays the PL spectra taken during several time intervals that evidence that the broad emission at $500 \mathrm{~nm}$ decays within $1 \mu \mathrm{s}$. It is remarkable that for these concentrations no such broad emission at $500 \mathrm{~nm}$ can be observed beyond $1 \mu \mathrm{s}$ (also in the glass of Figure $5 \mathrm{~b}$ ), even though phosphorescence prevails on a milliseconds time scale. The lack of this broad emission and the rise of phosphorescence on a milliseconds time scale imply that aggregated molecules do not act as trap sites for triplet states. We could observe long-lived emission from aggregates, i.e., aggregate phosphorescence, only 

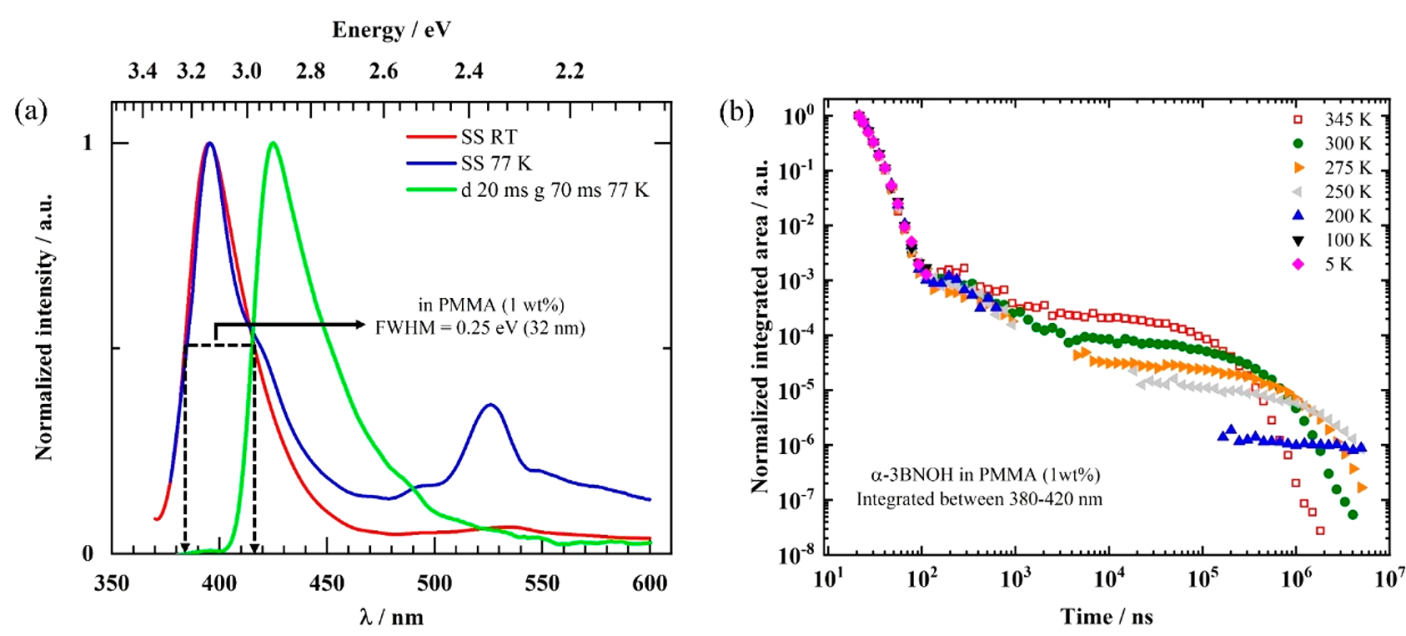

Figure 7. $\alpha$-3BNOH dispersed at $1 \mathrm{wt} \%$ into PMMA. (a) Spectra taken under steady-state conditions at room temperature (red line, SS RT) and at 77 $\mathrm{K}$ (blue line, SS $77 \mathrm{~K}$ ) and taken with a delay of $20 \mathrm{~ms}$ and a gate width of $70 \mathrm{~ms}$ at $77 \mathrm{~K}$ (green line). (b) Decay of the luminescence signal, spectrally integrated from 380 to $420 \mathrm{~nm}$, taken at different temperatures as indicated.

when using more concentrated solutions or in thin films. This is detailed in the Supporting Information (Figure S14a,b). In passing, we mention that the singlet-triplet splitting in the aggregate is very small, on the order of about $70 \mathrm{meV}$.

Figure 6 addresses the luminescence transients. In the blue spectral window from 380 to $420 \mathrm{~nm}$, the PL taken from a dilute $7.6 \times 10^{-5} \mathrm{M}$ solution shows a decay from prompt fluorescence followed by a delayed fluorescence component from about $50 \mathrm{~ns}$ onward (see Figure 6a). This DF decay has a very similar intensity at 5 and $100 \mathrm{~K}$, yet it reduces relative to the prompt fluorescence upon heating to 150 and $200 \mathrm{~K}$ (see Figure 6b). We note that the glass transition temperature $T_{\mathrm{g}}$ of THF is about $120 \mathrm{~K}$. The transient in the green-red spectral windows, 500$600 \mathrm{~nm}$, shows a similar evolution insofar that the 5 and $100 \mathrm{~K}$ decays coincide, yet the relative intensity reduces upon heating to 200 and $300 \mathrm{~K}$. The signal between 500 and $600 \mathrm{~nm}$ is due to aggregates, and we attribute the reduction of this signal upon heating to the dissociation of the aggregates with temperature. Recalling that for THF $T_{\mathrm{g}}$ is about $120 \mathrm{~K}$, it is clear that this process only sets in from about $150 \mathrm{~K}$ onward. From the observation that the signal between 380 and $420 \mathrm{~nm}$ reduces in parallel to the signal between 500 and $600 \mathrm{~nm}$ upon heating, we conclude that the existence of aggregates is a prerequisite for the delayed blue emission up to and including $300 \mathrm{~K}$.

The most likely origin is that the blue delayed fluorescence results from triplet-triplet annihilation (TTA) that can occur in the aggregated material, which forms despite the high dilution. We recall that at these concentrations the emissive aggregates do not provide a significant number of traps for the (monomer) triplet states. We have measured the dependence of the steadystate emission, i.e., the blue signal, on the excitation power and found this to be linear (Figure S15). While a linear power dependence is often considered to indicate a TADF process, we point out that this is evidently not the case here, as (i) the delayed fluorescence reduces upon heating up to $250 \mathrm{~K}$ instead of being thermally activated and (ii) its intensity evolution correlates with the aggregate concentration, while TADF should be independent of any aggregation effects. In fact, a linear power dependence is characteristic for TTA if the TTA process dominates over other radiative or nonradiative triplet decay channels. ${ }^{62}$ For pulsed excitation with triplet lifetimes of $30 \mathrm{~ms}$ or longer, this condition is easily fullfilled. This is confirmed by the time dependence of the DF signal. The $200 \mathrm{~K}$ signals shows the plateau followed by the $t^{-2}$ decay that is characteristic for the DF decay, which evolves as $\left(\left[\mathrm{T}_{0}\right] /\left(1+\left[\mathrm{T}_{0}\right] \gamma t\right)\right)^{2}$, where $\left[\mathrm{T}_{0}\right]$ is the initial triplet concentration and $\gamma$ is the annihilation constant. At lower temperatures, transport becomes increasingly dispersive, thus reducing the slope toward $t^{-1}$.

Having established that TTA prevails from $5 \mathrm{~K}$ to close to 300 $\mathrm{K}$, we now consider the temperature regime from $300 \mathrm{~K}$ onward (Figure 6c). It is evident that, upon heating, a thermally activated component emerges. Thus, it seems that there is a TADF component that becomes active above $300 \mathrm{~K}$. The crossover between the regimes where TTA and where TADF prevail is around room temperature. For the analysis of the TADF kinetics it is important to establish whether any contribution dominates at $300 \mathrm{~K}$. We have therefore measured the dependence of the decay transient on excitation power. A higher TTA rate due to a higher triplet concentration would alter the time where the plateau merges into the $t^{-2}$ decay. We observe no change in the decay transients upon increasing the fluence from 0.3 to $30 \mu \mathrm{J}$ for a spot size of $4 \mathrm{~mm}$ diameter, even when using a more concentrated solution where aggregation should be stronger (see Figure S16). This suggests that at $300 \mathrm{~K}$ and above the decay kinetics in the "shorter" time range up to a few microseconds is controlled mostly by a monomolecular process such as TADF. At longer times above a few microseconds, where the decay merges into a $t^{-2}$ dependence, TTA evidently still prevails. Figure 6d shows a fit to the PL decay considering a monoexponential decay with a fixed lifetime of 450 ns to account for TADF and a decay according to $\left[T_{0} /(1+\right.$ $\left.\left.T_{1} t\right)\right]^{2}$ to account for TTA. A fit to the prompt fluorescence yields a lifetime of about 9 ns. This and fits with other TADF lifetimes are available in the Supporting Information (Figure S16).

It is not possible to derive a rate for the reverse intersystem crossing, $k_{\mathrm{RISC}}$, from the dynamics described above. Simply inserting the lifetime into the frequently used equations from the Monkman group, as is sometimes done, would give a nominal value of about $2 \times 10^{6} \mathrm{~s}^{-1}$, which would be a high value for a $\Delta E_{\mathrm{ST}}$ of $0.31 \mathrm{eV} .^{67,68}$ However, as has also been stressed by the Monkman group, in deriving these equations a number of approximations are made that only hold when the quantum yield for $\mathrm{DF}, \Phi_{\mathrm{DF}}$, is about 4 times larger than that of the PF, $\Phi_{\mathrm{PF}}$. This 
Table 1. Lifetime Data and Excited-State Energies for $\alpha-3 B N O H$ in THF Solution and in Film

\begin{tabular}{|c|c|c|c|c|c|c|c|c|c|c|}
\hline & \multicolumn{5}{|c|}{ in $7.6 \times 10^{-5} \mathrm{M}$ THF solution } & \multicolumn{5}{|c|}{ at 1 wt $\%$ in PMMA } \\
\hline & $\tau_{\mathrm{p}}(\mathrm{ns})$ & $\tau_{\mathrm{d}}^{a}(\mathrm{~ns})$ & $E_{\mathrm{S} 1}^{b}(\mathrm{eV})$ & $E_{\mathrm{T} 1}^{c}(\mathrm{eV})$ & $\Delta E_{\mathrm{ST}}^{d}(\mathrm{eV})$ & $\tau_{\mathrm{p}}(\mathrm{ns})$ & $\tau_{\mathrm{d}}^{e}(\mu \mathrm{s})$ & $E_{\mathrm{S} 1}^{b}(\mathrm{eV})$ & $E_{\mathrm{T} 1}^{c}(\mathrm{eV})$ & $\Delta E_{\mathrm{ST}}^{d}(\mathrm{eV})$ \\
\hline$\alpha-3 \mathrm{BNOH}$ & 8.5 & 450 & 3.12 & 2.81 & 0.31 & 8.5 & 260 & 3.14 & 2.92 & 0.22 \\
\hline
\end{tabular}
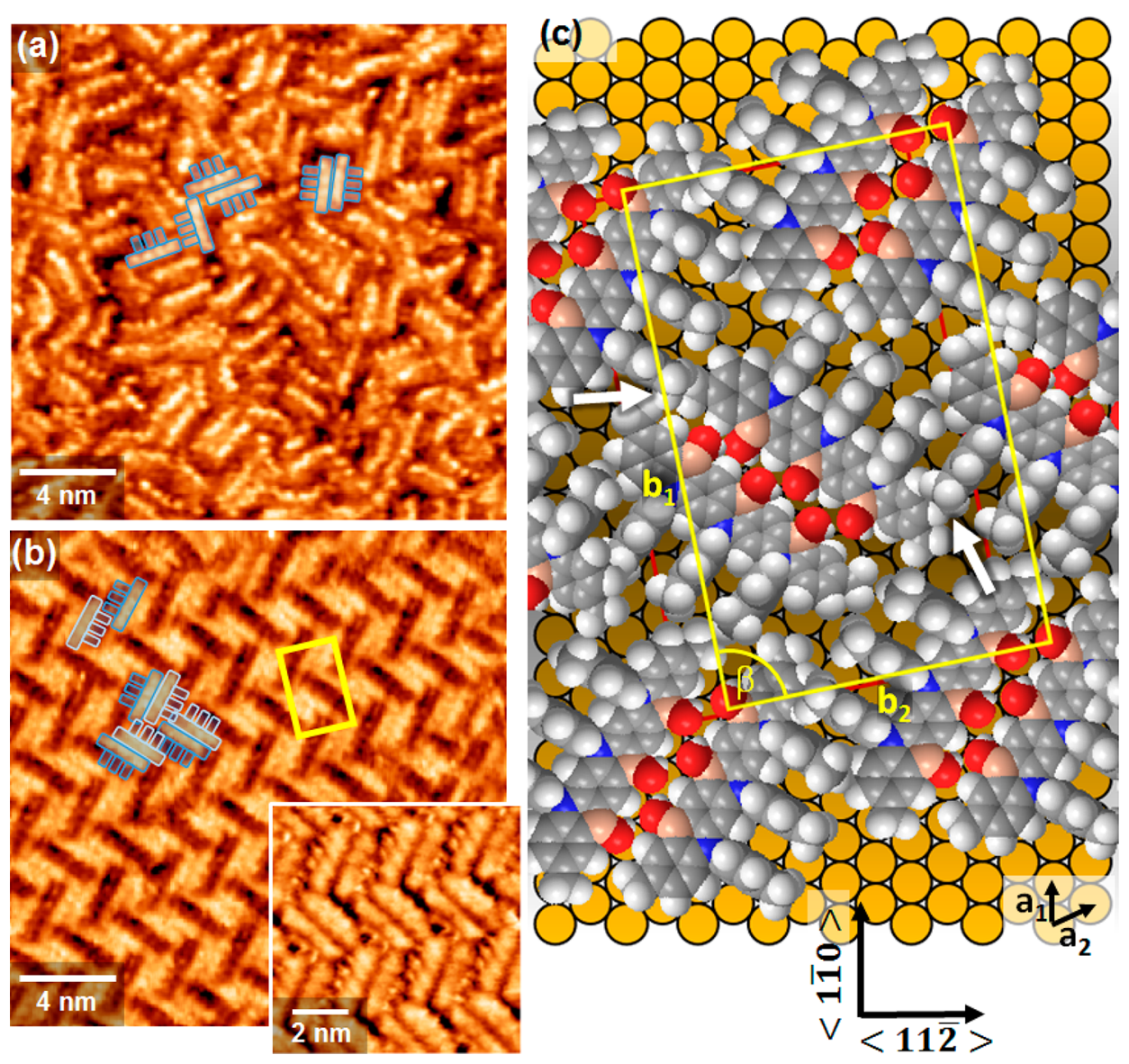

Figure 8. STM images of $\alpha-3 \mathrm{BNOH}$ monolayers on $\mathrm{Au}(111)$ prepared at $343 \mathrm{~K}$ from $400 \mu \mathrm{M}$ DMF solution (a) and at room temperature from 150 $\mu \mathrm{M}$ DMF solution (b) with inset showing the layer at different tunneling contrast. The footprint of the molecules and their packing is indicated by the blue shapes. (c) Space-filling model of the ordered structure shown in (b). Arrows point to sterically crowded sites. Yellow rectangles in (b) and (c) indicate the unit cell. Tunneling parameters $\left(U_{\text {tip }} / I\right):(a)+0.5 \mathrm{~V} / 40 \mathrm{pA},(\mathrm{b})+0.268 \mathrm{~V} / 30 \mathrm{pA}$ (large image), $+0.1 \mathrm{~V} / 0.1 \mathrm{nA}$ (inset).

is not the case for $\alpha$-3BNOH. Rather, in Figure $6 \mathrm{~d}, \Phi_{\mathrm{DF}} \approx$ $0.01 \Phi_{\mathrm{PF}}$, consistent with the $\Delta E_{\mathrm{ST}}$ value and previous MRTADF emitters. ${ }^{48,69}$ We note that the TADF component seems to have an activation energy of only about $70 \mathrm{meV}$ while the singlet-triplet splitting is in the range of $300 \mathrm{meV}$. This discrepancy has previously been accounted for by mixing with higher-lying excited states. ${ }^{68}$ SCS-CC2 calculations predict the presence of two higher-lying triplet states of energies intermediate between $T_{1}$ and $S_{1}$, each of which has MR-TADF character (Figure S12). Here, the low value may also relate to the fact that the TADF component superimposes on the TTA component. The reduction of the TTA contribution with increasing temperature due to the dissolution of any aggregates also reduces the observed increase in TADF, and the two processes are difficult to disentangle.

For electroluminescent device applications, it is essential to know how these properties translate into films. Figure 7 shows the spectra and transients obtained for $\alpha-3 \mathrm{BNOH}$ dispersed (doped) at 1 wt \% into poly(methyl methacrylate) (PMMA).

Comparison with the solution spectra shown in Figures 4 and 5 shows that the long-lived component peaking at about $425 \mathrm{~nm}$ $(2.92 \mathrm{eV})$ at $77 \mathrm{~K}$ is the phosphorescence signal, and the shortlived band peaking around $395 \mathrm{~nm}(3.14 \mathrm{eV})$ is the fluorescence. In the PMMA matrix, the ratio between the integrated delayed fluorescence signal and the integrated prompt fluorescence increases significantly, so that $\Phi_{\mathrm{DF}} \approx 0.20 \Phi_{\mathrm{PF}}$. The FWHM is $0.25 \mathrm{eV}(32 \mathrm{~nm})$, i.e., nearly unaltered compared to the value in solution. The singlet-triplet gap, $\Delta E_{\mathrm{ST}}$, in the $1 \mathrm{wt} \%$ emitter doped in PMMA film is $0.22 \mathrm{eV}$, which is about $100 \mathrm{meV}$ smaller compared to that in THF solution. Such shifts are common for charge-transfer type states and result from different polarities of the solvent and matrix. The short-lived feature at $525 \mathrm{~nm}$ observed at $77 \mathrm{~K}$ is some emission from remnant excimers or aggregates that disappears below a microseconds time scale (see Figure S17). It is gratifying that this does not prevail at room 
temperature, thus preserving the deep blue emission color with CIE coordinates of $x=0.17$ and $y=0.01$ when dispersed at $1 \mathrm{wt}$ $\%$ in PMMA. This represents a blue-shift compared to DABNA$1,{ }^{48}$ which has CIE coordinates of $(0.13,0.09)$ in the electroluminescent device, at the expense of a slightly larger FWHM $(0.25 \mathrm{eV}$ or $32 \mathrm{~nm}$ for $\alpha-3 \mathrm{BNOH}$ compared to $0.20 \mathrm{eV}$ or $28 \mathrm{~nm}$ for DABNA-1 in the OLED).

The PL transients of the doped film show three distinct regimes. First, we observe a prompt decay component with a lifetime of $8.5 \mathrm{~ns}$, identical to that in solution. Second, from about $100 \mathrm{~ns}$ to several microseconds we observe a decay of unclear origin. Finally, toward longer times there is an exponential decay that is temperature activated. At room temperature, the lifetime of this monoexponential decay is about $260 \mu$ s (see Figure S18a). Evaluating the thermal activation of the long-lived decay gives an activation energy of $220 \mathrm{meV}$, which matches with the observed $\Delta E_{\mathrm{ST}}$ (see Figure S18c). It does not show any dependence on incident light intensity (see Figure S18b), identifying it as a monomolecular process. This, in combination with the thermal activation with an energy that matches the singlet-triplet splitting, strongly suggests the 260 $\mu$ s lifetime to be a TADF signal. If fitted with a singleexponential decay, then the signal in the intermediate range from about $100 \mathrm{~ns}$ to several microseconds has a lifetime on the order of $0.5 \mu \mathrm{s}$, though an interpretation as a dispersive decay following a $t^{-1}$ law would also be possible. It shows a small dependence on intensity (see Figure S18b). Evidently, more detailed follow-up studies beyond the scope of this investigation are required to unambiguously assign this intermediate feature. The photophysical data in solution and film are summarized in Table 1. Solvatochromic measurements have also been performed in solution (Figure S19), yet they show no systematic shift with solvent polarity, in agreement with the short-range charge transfer observed in the $S_{1}$ excited state (see Figure 3).

We next performed scanning tunneling microscopy (STM) measurements to study the self-assembly process of $\alpha-3 \mathrm{BNOH}$ on $\mathrm{au}(111)$ surface. The focus was on the first layer which, through templating and modification of chemical interactions, is critical for the growth of thin films. ${ }^{70-72}$ Samples prepared at two different temperatures (RT and $343 \mathrm{~K}$ ) and a range of concentrations were investigated. The STM images at submolecular resolution of layers prepared from solutions of $\alpha-3 \mathrm{BNOH}$ (Figure 8) reveal a pronounced influence of concentration on the order of the layers as illustrated in Figure 8 whereas no noticeable influence of the preparation temperature was observed. Higher concentrations yield disordered layers as evidenced by Figure 8a. In contrast, a highly crystalline herringbone structure is formed at the lower concentration (Figure $8 \mathrm{~b}$ ), and in the intermediate concentration range above $200 \mu \mathrm{M}$ the two morphologies can coexist. In the STM images of both the disordered and crystalline layers of the individual molecules are clearly discernible with some of them overlaid by a footprint of the molecules outlining the acene backbone and the three tolyl units. It is noted that the submolecular resolution is dependent on tip conditions as well as tunneling parameters. In the disordered layer the four benzene rings of the heptacene backbone are clearly resolved. A somewhat different tunneling contrast is seen in the large image of the crystalline layer where, even though less pronounced, the backbone is still resolved but also individual tolyl moieties show up as protrusions. The latter become even more clear using another set of tunneling parameters (inset of Figure $8 b$ ).
The basic units of the ordered layer consist of dimers with two achiral $\alpha-3 \mathrm{BNOH}$ molecules arranged in a staggered fashion to yield two chiral enantiomeric entities. As seen from the molecular model displayed in Figure 8c, such a dimerization is favored by the contour of the molecules and their supramolecular interactions comprising $\mathrm{OH} \cdots \mathrm{H}$ and $\mathrm{C}-\mathrm{H} \cdots \mathrm{O}$ bonding. The herringbone structure is the result of an alternating arrangement of the enantiomeric dimers. While a herringbone packing has been observed for other acene monolayers like rubrene ${ }^{73}$ or pentacene, ${ }^{74}$ the present case is different as instead of an achiral monomer chiral dimers are the units underlying the structure. The formation of dimers is impeded at the higher concentration due to kinetic barriers arising from interlocking of the molecules before they can arrange into an ordered structure. This evidences that pairing of the molecules is a process occurring at the surface and not in the bulk solution.

Looking at the structural model of Figure $8 \mathrm{c}$, the major intermolecular interactions in the monolayers are those resulting in dimer formation. Interactions between different dimers seem to be comparably weak, even though not negligible as the alignment of the tolyl groups of adjacent molecules suggest as illustrated in the top left corner of Figure $8 \mathrm{~b}$. Also, sterical hindrance is likely to play a role (sites marked by arrows in Figure $8 \mathrm{c}$ ), which would require some conformational adjustment. Therefore, the interaction between the acene backbone and the metal surface is considered the major driving force to minimize the energy of the system by maximizing coverage. Other dimer arrangements such as a linear structure mediated by interactions of tolyl moieties would result in a more open structure and, therefore, a lower coverage. The registry between substrate and lattice of the $\alpha-3 \mathrm{BNOH}$ layer also plays a role as domains are aligned along well-defined directions of the substrate. On the basis of the STM data, the unit cell marked by the yellow rectangles is proposed. Containing four molecules (211 $\AA^{2}$ per molecule), it is an essentially rectangular unit cell w i t h p a r a m e t e r s of $b_{1}=\sqrt{163} a=36.9 \AA, b_{2}=3 \sqrt{7} a=22.9 \AA(a$ as the unit cell parameter of the $\mathrm{Au}(111)$ surface, $2.89 \AA)$, and $\beta=90.8^{\circ}$, in matrix notation $(14-3,-39)$. This means the presence of mirror domains with $b_{2}$ off the $\langle 11 \overline{2}\rangle$ direction by $\pm 10.9^{\circ}$. While it is well-known that achiral molecules can assemble on surfaces to form chiral domains, ${ }^{75} \alpha-3 \mathrm{BNOH}$ is different as mirror domains are enantiomorphic structures of racemix mixtures of the chiral dimers, analogous to the case of heptahelicenes where this has been observed for a mixture of enantiomeric monomers. ${ }^{76}$ As far as the assembly process is concerned, it is not clear at present whether the dimers preform and attach to or individual molecules lock into a growing domain. Detailed concentration-dependent studies will provide further insight into the mechanism of film formation.

\section{CONCLUSIONS}

In summary, a linearly extended B,N-doped heptacene ( $\alpha$ $3 \mathrm{BNOH})$ has been synthesized via electrophilic arene borylation. Starting from $p$-toluidine, we obtained $\alpha-3 \mathrm{BNOH}$ in three steps in good yields through easy-to-access chemical reactions. High thermal stabilty $\left(T_{\mathrm{d}}=554{ }^{\circ} \mathrm{C}\right)$ was exhibited by this compound. The multiresonant TADF property of $\alpha$ $3 \mathrm{BNOH}$ has been investigated by combining results from stateof-the art quantum-chemical calculations and temperaturedependent emission decay measurements. Our heptacene 
derivative presents a near-UV emission profile in solutions with a narrow emission band. Compared to the reported MR-TADF emitter $v$-DABNA, which is by far the highest performing MRTADF compound in terms of a fast fluorescence rate $\left(k_{\mathrm{F}}=2.0 \times\right.$ $\left.10^{8} \mathrm{~s}^{-1}\right)$ short delayed lifetime $\left(\tau_{\mathrm{d}}=4.1 \mu \mathrm{s}\right)$ and efficient rISC $\left(k_{\mathrm{RISC}}=2.0 \times 10^{5} \mathrm{~s}^{-1}\right),{ }^{46} \alpha-3 \mathrm{BNOH}$ possesses an order of magnitude shorter delayed lifetime of only $450 \pm 10 \mathrm{~ns}$ in solution. In thin films, the deep blue color with CIE coordinates of $(0.17,0.01)$ is gratifyingly preserved. $\alpha-3 \mathrm{BNOH}$ thus essentially possesses the optoelectronic requirement for a deep blue TADF material in terms of high band gap. In addition, $\alpha$ $3 \mathrm{BNOH}$ presented an attractive combination of TADF and TTA in a single material, which can lead to a hybrid, long-lived, and highly efficient deep blue material for OLEDs. With the help of theoretical calculations we demonstrated the dependence of $\Delta E_{\mathrm{ST}}$ and optical energy gap in linear, heteroatom-doped acenes through controlling the position of donor and acceptor atoms in the acene core. Finally, the quality of $\alpha-3 \mathrm{BNOH}$ layers on a $\mathrm{Au}(111)$ surface is critically dependent on the preparation conditions. Remarkably, a highly crystalline layer exhibiting a hierarchical organization of the achiral molecule to enantiomeric dimers and ordering to a racemic chiral structure is observed.

\section{ASSOCIATED CONTENT}

\section{(s) Supporting Information}

The Supporting Information is available free of charge at https://pubs.acs.org/doi/10.1021/jacs.9b13704.

${ }^{1} \mathrm{H}$ NMR, ${ }^{13} \mathrm{C} \mathrm{NMR}$, and HRMS spectra of all new compounds; supplementary computational data and coordinates; supplementary photophysical data (PDF)

Crystallographic data for $\alpha-3 \mathrm{BNOH}$ (CIF)

\section{AUTHOR INFORMATION}

\section{Corresponding Authors}

Eli Zysman-Colman - Organic Semiconductor Centre, EaStCHEM School of Chemistry, University of St. Andrews, St. Andrews, U.K. KY16 9ST; 10 orcid.org/0000-0001-71836022; Email: eli.zysman-colman@st-andrews.ac.uk

Anna Köhler - Soft Matter Optoelectronics, University of Bayreuth, 95447 Bayreuth, Germany; 이이이.org/0000-00015029-4420; Email: anna.koehler@uni-bayreuth.de

Manfred Buck - Organic Semiconductor Centre, EaStCHEM School of Chemistry, University of St. Andrews, St. Andrews, U.K. KY16 9ST; Email:mb45@st-andrews.ac.uk

Yoann Olivier - Laboratory for Chemistry of Novel Materials, University of Mons, 7000 Mons, Belgium; Unite de Chimie Physique Théorique et Structurale \& Laboratoire de Physique du Solide, Namur Institute of Structured Matter, Universite de Namur, 5000 Namur, Belgium; Email: yoann.olivier@ unamur.be

\section{Authors}

Subeesh Madayanad Suresh - Organic Semiconductor Centre, EaStCHEM School of Chemistry, University of St. Andrews, St. Andrews, U.K. KY16 9ST

Eimantas Duda - Soft Matter Optoelectronics, University of Bayreuth, 95447 Bayreuth, Germany

David Hall - Organic Semiconductor Centre, EaStCHEM School of Chemistry, University of St. Andrews, St. Andrews, U.K. KY16 9ST; Laboratory for Chemistry of Novel Materials, University of Mons, 7000 Mons, Belgium
Zhen Yao - Organic Semiconductor Centre, EaStCHEM School of Chemistry, University of St. Andrews, St. Andrews, U.K. KY16 9ST

Sergey Bagnich - Soft Matter Optoelectronics, University of Bayreuth, 95447 Bayreuth, Germany

Alexandra M. Z. Slawin - Organic Semiconductor Centre, EaStCHEM School of Chemistry, University of St. Andrews, St. Andrews, U.K. KY16 9ST

Heinz Bässler - BIMF, University of Bayreuth, 95447 Bayreuth, Germany

David Beljonne - Laboratory for Chemistry of Novel Materials,

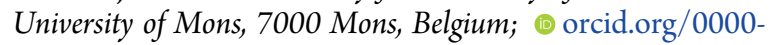
0002-2989-3557

Complete contact information is available at:

https://pubs.acs.org/10.1021/jacs.9b13704

\section{Notes}

The authors declare no competing financial interest.

The research data supporting this publication can be accessed at https: / / doi.org/10.17630/61d22464-e20e-4914-a7ff31e2858034a6

\section{ACKNOWLEDGMENTS}

We thank the Leverhulme Trust (RPG-2016-047). This project has received funding from the European Union's Horizon 2020 research and innovation programme under the Marie Skłodowska Curie grant agreement no. 838885 (NarrowbandSSL) and 812872 (TADFlife). We thank Umicore for their generous supply of catalysts. S.S. acknowledges support from the Marie Skłodowska-Curie Individual Fellowship. S.B. acknowledges support from the Bayrisches Staatsministerium für Wissenschaft und Kunst (Stmwk) in the framework of the initiative "SolTech" as well as from the German Science foundation (DFG) (no. 392306670). Z.Y. acknowledges support from the Chinese Scholarship Council (201606100044) and the University of St. Andrews through a stipend. Computational resources have been provided by the Consortium des Equipements de Calcul Intensif (CECI), funded by the Fonds de la Recherche Scientifiques de Belgique (F.R.S.-FNRS) under grant no. 2.5020.11, as well as the Tier-1 supercomputer of the Féderation Wallonie-Bruxelles, infrastructure funded by the Walloon Region under the grant agreement no. 1117545. The authors thank F. Rodella and Prof. P. Strohriegl from Bayreuth University for help with the thermogravimetric analysis.

\section{REFERENCES}

(1) Geim, A. K.; Novoselov, K. S. The rise of graphene. Nat. Mater. 2007, 6 (3), 183-191.

(2) Geim, A. K. Graphene: Status and Prospects. Science 2009, 324 (5934), 1530-1534.

(3) Lemine, A. S.; Zagho, M. M.; Altahtamouni, T. M.; Bensalah, N. Graphene a promising electrode material for supercapacitors-A review. Int. J. Energy Res. 2018, 42 (14), 4284-4300.

(4) Wang, X.-Y.; Narita, A.; Müllen, K. Precision synthesis versus bulkscale fabrication of graphenes. Nat. Rev. Chem. 2018, 2, 0100.

(5) Xu, B.; Yue, S.; Sui, Z.; Zhang, X.; Hou, S.; Cao, G.; Yang, Y. What is the choice for supercapacitors: graphene or graphene oxide? Energy Environ. Sci. 2011, 4 (8), 2826-2830.

(6) Fan, W.; Xia, Y.-Y.; Tjiu, W. W.; Pallathadka, P. K.; He, C.; Liu, T. Nitrogen-doped graphene hollow nanospheres as novel electrode materials for supercapacitor applications. J. Power Sources 2013, 243, 973-981. 
(7) Karthika, P.; Rajalakshmi, N.; Dhathathreyan, K. S. PhosphorusDoped Exfoliated Graphene for Supercapacitor Electrodes. J. Nanosci. Nanotechnol. 2013, 13 (3), 1746-1751.

(8) Yang, S.; Song, X.; Zhang, P.; Gao, L. Facile Synthesis of NitrogenDoped Graphene-Ultrathin $\mathrm{MnO} 2$ Sheet Composites and Their Electrochemical Performances. ACS Appl. Mater. Interfaces 2013, 5 (8), 3317-3322.

(9) Wu, Z.-S.; Ren, W.; Xu, L.; Li, F.; Cheng, H.-M. Doped Graphene Sheets As Anode Materials with Superhigh Rate and Large Capacity for Lithium Ion Batteries. ACS Nano 2011, 5 (7), 5463-5471.

(10) Zhang, C.; Mahmood, N.; Yin, H.; Liu, F.; Hou, Y. Synthesis of Phosphorus-Doped Graphene and its Multifunctional Applications for Oxygen Reduction Reaction and Lithium Ion Batteries. Adv. Mater. 2013, 25 (35), 4932-4937.

(11) Wang, Z.-L.; Xu, D.; Wang, H.-G.; Wu, Z.; Zhang, X.-B. In Situ Fabrication of Porous Graphene Electrodes for High-Performance Energy Storage. ACS Nano 2013, 7 (3), 2422-2430.

(12) Nethravathi, C.; Rajamathi, C. R.; Rajamathi, M.; Gautam, U. K.; Wang, X.; Golberg, D.; Bando, Y. N-Doped Graphene-VO2(B) Nanosheet-Built 3D Flower Hybrid for Lithium Ion Battery. ACS Appl. Mater. Interfaces 2013, 5 (7), 2708-2714.

(13) Qu, L.; Liu, Y.; Baek, J.-B.; Dai, L. Nitrogen-Doped Graphene as Efficient Metal-Free Electrocatalyst for Oxygen Reduction in Fuel Cells. ACS Nano 2010, 4 (3), 1321-1326.

(14) Gao, H.; Liu, Z.; Song, L.; Guo, W.; Gao, W.; Ci, L.; Rao, A.; Quan, W.; Vajtai, R.; Ajayan, P. M. Synthesis of S-doped graphene by liquid precursor. Nanotechnology 2012, 23 (27), 275605.

(15) Xu, J.; Dong, G.; Jin, C.; Huang, M.; Guan, L. Sulfur and nitrogen co-doped, few-layered graphene oxide as a highly efficient electrocatalyst for the oxygen-reduction reaction. ChemSusChem 2013, 6 (3), 493-499.

(16) Jeon, I.-Y.; Choi, H.-J.; Choi, M.; Seo, J.-M.; Jung, S.-M.; Kim, M.-J.; Zhang, S.; Zhang, L.; Xia, Z.; Dai, L.; Park, N.; Baek, J.-B. Facile, scalable synthesis of edge-halogenated graphene nanoplatelets as efficient metal-free eletrocatalysts for oxygen reduction reaction. Sci. Rep. 2013, 3, 1810.

(17) Li, X.; Fan, L.; Li, Z.; Wang, K.; Zhong, M.; Wei, J.; Wu, D.; Zhu, $\mathrm{H}$. Boron Doping of Graphene for Graphene-Silicon p-n Junction Solar Cells. Adv. Energy Mater. 2012, 2 (4), 425-429.

(18) Xue, Y.; Liu, J.; Chen, H.; Wang, R.; Li, D.; Qu, J.; Dai, L. Nitrogen-Doped Graphene Foams as Metal-Free Counter Electrodes in High-Performance Dye-Sensitized Solar Cells. Angew. Chem., Int. Ed. 2012, 51 (48), 12124-12127.

(19) Das, S.; Sudhagar, P.; Verma, V.; Song, D.; Ito, E.; Lee, S. Y.; Kang, Y. S.; Choi, W. Amplifying Charge-Transfer Characteristics of Graphene for Triiodide Reduction in Dye-Sensitized Solar Cells. Adv. Funct. Mater. 2011, 21 (19), 3729-3736.

(20) Kwon, O. S.; Park, S. J.; Hong, J.-Y.; Han, A. R.; Lee, J. S.; Lee, J. S.; Oh, J. H.; Jang, J. Flexible FET-Type VEGF Aptasensor Based on Nitrogen-Doped Graphene Converted from Conducting Polymer. ACS Nano 2012, 6 (2), 1486-1493.

(21) Wang, Y.; Shao, Y.; Matson, D. W.; Li, J.; Lin, Y. Nitrogen-Doped Graphene and Its Application in Electrochemical Biosensing. ACS Nano 2010, 4 (4), 1790-1798.

(22) Sheng, Z.-H.; Zheng, X.-Q.; Xu, J.-Y.; Bao, W.-J.; Wang, F.-B.; Xia, X.-H. Electrochemical sensor based on nitrogen doped graphene: Simultaneous determination of ascorbic acid, dopamine and uric acid. Biosens. Bioelectron. 2012, 34 (1), 125-131.

(23) Zhang, Y.-H.; Chen, Y.-B.; Zhou, K.-G.; Liu, C.-H.; Zeng, J.; Zhang, H.-L.; Peng, Y. Improving gas sensing properties of graphene by introducing dopants and defects: a first-principles study. Nanotechnology 2009, 20 (18), 185504.

(24) Cai, J.; Ruffieux, P.; Jaafar, R.; Bieri, M.; Braun, T.; Blankenburg, S.; Muoth, M.; Seitsonen, A. P.; Saleh, M.; Feng, X.; Müllen, K.; Fasel, $\mathrm{R}$. Atomically precise bottom-up fabrication of graphene nanoribbons. Nature 2010, 466 (7305), 470-473.

(25) Cloke, R. R.; Marangoni, T.; Nguyen, G. D.; Joshi, T.; Rizzo, D. J.; Bronner, C.; Cao, T.; Louie, S. G.; Crommie, M. F.; Fischer, F. R.
Site-Specific Substitutional Boron Doping of Semiconducting Armchair Graphene Nanoribbons. J. Am. Chem. Soc. 2015, 137 (28), 8872-8875.

(26) Kawai, S.; Saito, S.; Osumi, S.; Yamaguchi, S.; Foster, A. S.; Spijker, P.; Meyer, E. Atomically controlled substitutional borondoping of graphene nanoribbons. Nat. Commun. 2015, 6 (1), 8098.

(27) Sánchez-Sánchez, C.; Brüller, S.; Sachdev, H.; Müllen, K.; Krieg, M.; Bettinger, H. F.; Nicolaï, A.; Meunier, V.; Talirz, L.; Fasel, R.; Ruffieux, P. On-Surface Synthesis of BN-Substituted Heteroaromatic Networks. ACS Nano 2015, 9 (9), 9228-9235.

(28) Smalley, R. E.; Li, Y.; Moore, V. C.; Price, B. K.; Colorado, R.; Schmidt, H. K.; Hauge, R. H.; Barron, A. R.; Tour, J. M. Single Wall Carbon Nanotube Amplification: En Route to a Type-Specific Growth Mechanism. J. Am. Chem. Soc. 2006, 128 (49), 15824-15829.

(29) Fort, E. H.; Scott, L. T. One-Step Conversion of Aromatic Hydrocarbon Bay Regions into Unsubstituted Benzene Rings: A Reagent for the Low-Temperature, Metal-Free Growth of SingleChirality Carbon Nanotubes. Angew. Chem., Int. Ed. 2010, 49 (37), $6626-6628$

(30) Yu, X.; Zhang, J.; Choi, W.; Choi, J.-Y.; Kim, J. M.; Gan, L.; Liu, Z. Cap Formation Engineering: From Opened C60 to Single-Walled Carbon Nanotubes. Nano Lett. 2010, 10 (9), 3343-3349.

(31) Numano, M.; Nagami, N.; Nakatsuka, S.; Katayama, T.; Nakajima, K.; Tatsumi, S.; Yasuda, N.; Hatakeyama, T. Synthesis of Boronate-Based Benzo[fg]tetracene and Benzo[hi]hexacene via Demethylative Direct Borylation. Chem. - Eur. J. 2016, 22 (33), 11574-11577.

(32) Wang, X.-Y.; Narita, A.; Zhang, W.; Feng, X.; Müllen, K. Synthesis of Stable Nanographenes with OBO-Doped Zigzag Edges Based on Tandem Demethylation-Electrophilic Borylation. J. Am. Chem. Soc. 2016, 138 (29), 9021-9024.

(33) Hatakeyama, T.; Hashimoto, S.; Seki, S.; Nakamura, M. Synthesis of BN-Fused Polycyclic Aromatics via Tandem Intramolecular Electrophilic Arene Borylation. J. Am. Chem. Soc. 2011, 133 (46), 18614-18617.

(34) Hatakeyama, T.; Hashimoto, S.; Oba, T.; Nakamura, M. Azaboradibenzo[6]helicene: Carrier Inversion Induced by Helical Homochirality. J. Am. Chem. Soc. 2012, 134 (48), 19600-19603.

(35) Wang, X.; Zhang, F.; Liu, J.; Tang, R.; Fu, Y.; Wu, D.; Xu, Q.; Zhuang, X.; He, G.; Feng, X. Ladder-Type BN-Embedded Heteroacenes with Blue Emission. Org. Lett. 2013, 15 (22), 5714-5717.

(36) Wang, X.-Y.; Zhuang, F.-D.; Wang, X.-C.; Cao, X.-Y.; Wang, J.-Y.; $\mathrm{Pei}, \mathrm{J}$. Synthesis, structure and properties of C3-symmetric heterosuperbenzene with three BN units. Chem. Commun. 2015, 51 (21), $4368-4371$.

(37) Li, G.; Xiong, W.-W.; Gu, P.-Y.; Cao, J.; Zhu, J.; Ganguly, R.; Li, Y.; Grimsdale, A. C.; Zhang, Q. 1,5,9-Triaza-2,6,10-triphenylboracoronene: BN-Embedded Analogue of Coronene. Org. Lett. 2015, 17 (3), $560-563$.

(38) Crossley, D. L.; Cade, I. A.; Clark, E. R.; Escande, A.; Humphries, M. J.; King, S. M.; Vitorica-Yrezabal, I.; Ingleson, M. J.; Turner, M. L. Enhancing electron affinity and tuning band gap in donor-acceptor organic semiconductors by benzothiadiazole directed C-H borylation. Chem. Sci. 2015, 6 (9), 5144-5151.

(39) Crossley, D. L.; Vitorica-Yrezabal, I.; Humphries, M. J.; Turner, M. L.; Ingleson, M. J. Highly Emissive Far Red/Near-IR Fluorophores Based on Borylated Fluorene-Benzothiadiazole Donor-Acceptor Materials. Chem. - Eur. J. 2016, 22 (35), 12439-12448.

(40) Furukawa, S.; Kobayashi, J.; Kawashima, T. Development of a Sila-Friedel-Crafts Reaction and Its Application to the Synthesis of Dibenzosilole Derivatives. J. Am. Chem. Soc. 2009, 131 (40), 1419214193.

(41) Hashimoto, S.; Nakatsuka, S.; Nakamura, M.; Hatakeyama, T. Construction of a Highly Distorted Benzene Ring in a Double Helicene. Angew. Chem., Int. Ed. 2014, 53 (51), 14074-14076.

(42) Miyamoto, F.; Nakatsuka, S.; Yamada, K.; Nakayama, K.-i.; Hatakeyama, T. Synthesis of Boron-Doped Polycyclic Aromatic Hydrocarbons by Tandem Intramolecular Electrophilic Arene Borylation. Org. Lett. 2015, 17 (24), 6158-6161. 
(43) Fujimoto, K.; Oh, J.; Yorimitsu, H.; Kim, D.; Osuka, A. Directly Diphenylborane-Fused Porphyrins. Angew. Chem., Int. Ed. 2016, 55 (9), 3196-3199.

(44) Wang, X.; Zhang, F.; Schellhammer, K. S.; Machata, P.; Ortmann, F.; Cuniberti, G.; Fu, Y.; Hunger, J.; Tang, R.; Popov, A. A.; Berger, R.; Müllen, K.; Feng, X. Synthesis of NBN-Type Zigzag-Edged Polycyclic Aromatic Hydrocarbons: 1,9-Diaza-9a-boraphenalene as a Structural Motif. J. Am. Chem. Soc. 2016, 138 (36), 11606-11615.

(45) Hirai, H.; Nakajima, K.; Nakatsuka, S.; Shiren, K.; Ni, J.; Nomura, S.; Ikuta, T.; Hatakeyama, T. One-Step Borylation of 1,3-Diaryloxybenzenes Towards Efficient Materials for Organic Light-Emitting Diodes. Angew. Chem., Int. Ed. 2015, 54 (46), 13581-13585.

(46) Kondo, Y.; Yoshiura, K.; Kitera, S.; Nishi, H.; Oda, S.; Gotoh, H.; Sasada, Y.; Yanai, M.; Hatakeyama, T. Narrowband deep-blue organic light-emitting diode featuring an organoboron-based emitter. Nat. Photonics 2019, 13 (10), 678-682.

(47) Nakatsuka, S.; Gotoh, H.; Kinoshita, K.; Yasuda, N.; Hatakeyama, T. Divergent Synthesis of Heteroatom-Centered 4,8,12Triazatriangulenes. Angew. Chem., Int. Ed. 2017, 56 (18), 5087-5090.

(48) Hatakeyama, T.; Shiren, K.; Nakajima, K.; Nomura, S.; Nakatsuka, S.; Kinoshita, K.; Ni, J.; Ono, Y.; Ikuta, T. Ultrapure Blue Thermally Activated Delayed Fluorescence Molecules: Efficient HOMO-LUMO Separation by the Multiple Resonance Effect. Adv. Mater. 2016, 28 (14), 2777-2781.

(49) Matsui, K.; Oda, S.; Yoshiura, K.; Nakajima, K.; Yasuda, N.; Hatakeyama, T. One-Shot Multiple Borylation toward BN-Doped Nanographenes. J. Am. Chem. Soc. 2018, 140 (4), 1195-1198.

(50) Han, S. H.; Jeong, J. H.; Yoo, J. W.; Lee, J. Y. Ideal blue thermally activated delayed fluorescence emission assisted by a thermally activated delayed fluorescence assistant dopant through a fast reverse intersystem crossing mediated cascade energy transfer process. J. Mater. Chem. C 2019, 7 (10), 3082-3089.

(51) Pershin, A.; Hall, D.; Lemaur, V.; Sancho-Garcia, J.-C.; Muccioli, L.; Zysman-Colman, E.; Beljonne, D.; Olivier, Y. Highly emissive excitons with reduced exchange energy in thermally activated delayed fluorescent molecules. Nat. Commun. 2019, 10 (1), 597.

(52) Hirai, M.; Tanaka, N.; Sakai, M.; Yamaguchi, S. Structurally Constrained Boron-, Nitrogen-, Silicon-, and Phosphorus-Centered Polycyclic $\pi$-Conjugated Systems. Chem. Rev. 2019, 119 (14), 82918331.

(53) Agou, T.; Kobayashi, J.; Kawashima, T. Syntheses, Structure, and Optical Properties of Ladder-Type Fused Azaborines. Org. Lett. 2006, 8 (11), 2241-2244

(54) Sambiagio, C.; Marsden, S. P.; Blacker, A. J.; McGowan, P. C. Copper catalysed Ullmann type chemistry: from mechanistic aspects to modern development. Chem. Soc. Rev. 2014, 43 (10), 3525-3550.

(55) Ruiz-Castillo, P.; Buchwald, S. L. Applications of PalladiumCatalyzed C-N Cross-Coupling Reactions. Chem. Rev. 2016, 116 (19), 12564-12649.

(56) Connelly, N. G.; Geiger, W. E. Chemical Redox Agents for Organometallic Chemistry. Chem. Rev. 1996, 96 (2), 877-910.

(57) Cardona, C. M.; Li, W.; Kaifer, A. E.; Stockdale, D.; Bazan, G. C. Electrochemical Considerations for Determining Absolute Frontier Orbital Energy Levels of Conjugated Polymers for Solar Cell Applications. Adv. Mater. 2011, 23 (20), 2367-2371.

(58) Gierschner, J.; Cornil, J.; Egelhaaf, H.-J. Optical Bandgaps of $\pi$ Conjugated Organic Materials at the Polymer Limit: Experiment and Theory. Adv. Mater. 2007, 19 (2), 173-191.

(59) Gierschner, J.; Mack, H.-G.; Lüer, L.; Oelkrug, D. Fluorescence and absorption spectra of oligophenylenevinylenes: Vibronic coupling, band shapes, and solvatochromism. J. Chem. Phys. 2002, 116 (19), $8596-8609$.

(60) Marcus, M.; Milward, J. D.; Köhler, A.; Barford, W. Structural Information for Conjugated Polymers from Optical Modeling. J. Phys. Chem. A 2018, 122 (14), 3621-3625.

(61) Raithel, D.; Simine, L.; Pickel, S.; Schötz, K.; Panzer, F.; Baderschneider, S.; Schiefer, D.; Lohwasser, R.; Köhler, J.; Thelakkat, M.; Sommer, M.; Köhler, A.; Rossky, P. J.; Hildner, R. Direct observation of backbone planarization via side-chain alignment in single bulky-substituted polythiophenes. Proc. Natl. Acad. Sci. U. S. A. 2018, 115 (11), 2699.

(62) Köhler, A.; Bässler, H. The Electronic Structure of Organic Semiconductors. In Electronic Processes in Organic Semiconductors; Wiley-VCH: 2015.

(63) Mondal, R.; Tönshoff, C.; Khon, D.; Neckers, D. C.; Bettinger, H. F. Synthesis, Stability, and Photochemistry of Pentacene, Hexacene, and Heptacene: A Matrix Isolation Study. J. Am. Chem. Soc. 2009, 131 (40), 14281-14289.

(64) Payne, M. M.; Parkin, S. R.; Anthony, J. E. Functionalized Higher Acenes: Hexacene and Heptacene. J. Am. Chem. Soc. 2005, 127 (22), $8028-8029$.

(65) Xiao, Y.; Mague, J. T.; Schmehl, R. H.; Haque, F. M.; Pascal, R. A., Jr. Dodecaphenyltetracene. Angew. Chem., Int. Ed. 2019, 58 (9), 2831-2833.

(66) Müller, M.; Rüdiger, E. C.; Koser, S.; Tverskoy, O.; Rominger, F.; Hinkel, F.; Freudenberg, J.; Bunz, U. H. F. Butterfly Wings" Stabilize Heptacene. Chem. - Eur. J. 2018, 24 (32), 8087-8091.

(67) Haase, N.; Danos, A.; Pflumm, C.; Morherr, A.; Stachelek, P.; Mekic, A.; Brütting, W.; Monkman, A. P. Kinetic Modeling of Transient Photoluminescence from Thermally Activated Delayed Fluorescence. J. Phys. Chem. C 2018, 122 (51), 29173-29179.

(68) Dias, F. B.; Santos, J.; Graves, D. R.; Data, P.; Nobuyasu, R. S.; Fox, M. A.; Batsanov, A. S.; Palmeira, T.; Berberan-Santos, M. N.; Bryce, M. R.; Monkman, A. P. The Role of Local Triplet Excited States and D-A Relative Orientation in Thermally Activated Delayed Fluorescence: Photophysics and Devices. Advanced Science 2016, 3 (12), 1600080

(69) Hall, D.; Suresh, S. M.; dos Santos, P. L.; Duda, E.; Bagnich, S.; Pershin, A.; Rajamalli, P.; Cordes, D. B.; Slawin, A. M. Z.; Beljonne, D.; Köhler, A.; Samuel, I. D. W.; Olivier, Y.; Zysman-Colman, E. Improving Processability and Efficiency of Resonant TADF Emitters: A Design Strategy. Adv. Opt. Mater. 2020, 8 (2), 1901627.

(70) Kanjilal, A.; Ottaviano, L.; Di Castro, V.; Beccari, M.; Betti, M. G.; Mariani, C. Pentacene Grown on Self-Assembled Monolayer: Adsorption Energy, Interface Dipole, and Electronic Properties. J. Phys. Chem. C 2007, 111 (1), 286-293.

(71) Mänz, A.; Hauke, A. A.; Witte, G. Copper Phthalocyanine as Contact Layers for Pentacene Films Grown on Coinage Metals. J. Phys. Chem. C 2018, 122 (4), 2165-2172.

(72) Skomski, D.; Tait, S. L. Interfacial Organic Layers for Chemical Stability and Crystalline Ordering of Thiophene and Carboxyl Films on a Metal Surface. J. Phys. Chem. C 2014, 118 (3), 1594-1601.

(73) Luo, S. R.; Yau, S. L.; Kumaresan, P.; Vegiraju, S.; Chen, M.-C. Scanning Tunneling Microscopy Examination of Rubrene Deposited on $\mathrm{Au}(111)$ in Aqueous Solution. J. Phys. Chem. C 2015, 119 (3), $1376-1381$

(74) Smerdon, J.; Bode, M.; Guisinger, N.; Guest, J. Monolayer and bilayer pentacene on $\mathrm{Cu}(111)$. Phys. Rev. B: Condens. Matter Mater. Phys. 2011, 84, 165436.

(75) Barlow, S. M.; Raval, R. Complex organic molecules at metal surfaces: bonding, organisation and chirality. Surf. Sci. Rep. 2003, 50 (6), 201-341.

(76) Fasel, R.; Parschau, M.; Ernst, K.-H. Amplification of chirality in two-dimensional enantiomorphous lattices. Nature 2006, 439 (7075), 449-452. 